\title{
Validating a Measure of Productive Organisational Energy in the South African Context
}

\author{
Rowenna Cuff \\ Department of Human Resource Management, University of Pretoria, South Africa, 0002 \\ rowenna.cuff@gmail.com \\ Nicolene Barkhuizen
}

Department of Industrial Psychology, North-West University, Mmabatho, South Africa, 2745 nicolene.barkhuizen@nwu.ac.za

\section{Doi:10.5901/mjss.2014.v5n4p263}

\section{Abstract}

\begin{abstract}
Despite the inroads that are currently being made into research in the area of organisational energy, measuring instruments for this construct remain scant. This research explores the construct of POE with the aim to determine whether significant differences exist in the respondents perceptions of $P O E$ based on their biographical characteristics. A cross-sectional survey design was used, with a convenience sample $(N=302)$ taken from various demographic groups. The Productive Energy Measure was administered. Exploratory factor analysis with target rotations resulted in a three-factor model of productive organizational energy, consisting of the Cognitive, Affective and Behavioral Dimensions of Productive Organizational Energy. The scales showed acceptable internal consistencies and construct equivalence for the Black and White ethnic groups. This research provided evidence of the utility of the Productive Energy Measure in the South African context as a diagnostic tool for assessing the levels of productive organisation energy in organizations. The research makes an important contribution towards the field of Positive Psychology and Social Sciences by exploring and confirming productive organisational energy as a construct that can be used to assess positive psychological states in the workplace.
\end{abstract}

Keywords: Productive Organisational Energy, Productive Energy Measure, Positive Organisational Behaviour, Validation

\section{Introduction}

The increased pace, complexity and intensity of the global business environment in which individuals and organizations must function has led to changes in the way in which employees are viewed and managed (Bell \& Barkhuizen, 2011; Brown, 2011; Cummings \& Worley, 2008; Lawler \& Mohrman, 2003). The realization that the thoughts and emotions of employees play an important role in shaping the actions of employees in the workplace (Bruch \& Ghoshal, 2003; Bruch \& Vogel, 2011; Cameron \& Spreitzer, 2011, Cole, Bruch \& Vogel, 2012; Luthans \& Avolio, 2009) has resulted in increased scrutiny of the effects that positive psychological states can have in the workplace (Luthans \& Avolio, 2009) and the impact that these states can have on encouraging employee activities and behaviors that are needed to implement the organization's strategy effectively (Lawler, 2005).

Looking at the organization and organisational behavior from this perspective, the concept of energy becomes a valuable tool to gain a deeper understanding of how organizations can reach their full potential (Bruch \& Ghoshal, 2003; Bruch \& Vogel, 2011; Vogel \& Bruch, 2011). There is some evidence to suggest that organizational energy can yield various benefits for organizations and its employees. For the individual, organisational energy can result in increased health and well-being, employee motivation and commitment, job satisfaction, performance and creativity and teamwork (see Barkhuizen \& Stanz, 2010; Derman, 2009; Dutton, 2003; Bruch \& Vogel, 2011; Cross, Baker \& Parker, 2003; Schiuma, Mason \& Kennerly, 2007; Vogel \& Bruch, 2011). At the organizational level an energized workforce can lead to increased productivity and the achievement of key strategic goals and competitive advantage (Bruch \& Vogel, 2011; Vogel \& Bruch, 2011).

Despite the inroads that are currently being made into research in the area of organisational energy, measuring instruments for this construct remain scant (Vogel \& Bruch, 2011). Scholars in the field of organizational energy are of the opinion that the lack of a valid and reliable measurement instrument hampers the development of the field (Cole, et al., 2012). The aim of this research is to validate the Productive Energy Measure (Cole, Bruch \& Vogel, 2005; 2012) in the South African context, and to determine whether construct equivalence was present for White and African ethnic 
groups. South Africa is an inherently heterogeneous culture, and as a result researchers should exercise caution when applying measurement instruments developed overseas in the South African context (Meiring, et al., 2006). It is important that instruments developed and validated overseas are re-validated for use in the South African cultural context to ensure that construct and measurement equivalence and ultimately comparability are established. The psychometric properties of a measurement instrument have a significant impact on the interpretation of research data collected by means of the instrument (Furr, 2011). Therefore, it is important to understand the psychometric context of a measurement instrument so that meaningful conclusions can be drawn from the data, and generalized back to the population of interest.

This article is structured as follows. First we present an overview of Productive organisational energy and its measurement. This is followed by a discussion of the research method employed for this study. Flowing from the method the empirical results of the research are reported. The research concludes with a discussion of the results and recommendations for both practice and future research.

\section{Theory and Hypotheses}

\subsection{Productive Organisational Energy}

The concept of productive organisational energy was developed and coined by Cole et al (2005, p. 9). Productive organisational energy is a multi-dimensional construct and can be defined as a "joint experience and demonstration of positive affect, cognitive activation and agentic behavior among members of a collective in their shared pursuit of organizationally salient objectives" (Cole et al., 2005, p. 9). In essence, the productive organizational energy construct consist of three energies: Affective energy, Cognitive Energy and Behavioral Energy (see Cole et al., 2005; 2008; 2012). Although organizational energy occurs on the individual level, it also makes its presence felt as a shared or collective experience at higher levels, such as in a group or at the organizational level (Cole et al., 2012).

Affective energy results from the positive appraisal of work-related situations and experiences. According to Shirom $(2003$, p. 4) affect is a "highly structured response to a specific type of event or environmental interaction that gives rise to a characteristic adaptive behavior what is relevant to the needs, goals or survival of the organization". Affect energy manifests as emotional arousal, homogeneous levels of positive responses within the work group and constructive feelings such as inspiration, enthusiasm and attentiveness towards work-related tasks and organizational priorities (Cole, et al., 2005; 2012).

Cognitive energy refers to the intellectual processes drive group members to think constructively about workrelated problems and to persevere in the search for solutions (Vogel \& Bruch, 2011). In essence group members share the experience of being cognitively aroused and mentally alert in the search for shared goals (Vogel \& Bruch, 2011). Shared cognitive energy in groups can result in effective team processes, more optimistic attitudes, enhanced organisational outcomes (Cannon-Bowers \& Salas, 2001), and superior adaptation to dynamic environments (Salas \& Fiore, 2004).

Behavioural energy represents the action-related construct of productive organisational energy and the degree to which groups engage in active, focused, and purposeful behaviours to realize organizational objectives (Spreitzer, Sutcliffe, Dutton, Sonenshein \& Grant, 2005; Vogel \& Bruch, 2011). Individual behavior and social interactions are important drivers of energy creation for sustained business process execution and business performance (Schiuma et al., 2007). Behavioural energy is directly connected to the amount and intensity of the physical resources which employees devote to behaviors that benefit the organization (Cole, et al., 2012).

\subsection{Measuring Productive Organisational Energy}

Cole et al. (2005) developed the Productive Organisational Energy Measure to assess organizational energy as perceived by the individual. The results of the measure are materialized on a collective level by incorporating the scores of the Affective, Cognitive and Behavioral dimensions. Three separate studies were conducted to validate the PEM. The PEM was validated in multinational organizations, with five countries taking part in the validation study, namely France, Sweden, Switzerland, the United Kingdom and the United States (Cole, et al., 2012). The questionnaire was administered both in English and the local language spoken by the employees. Exploratory Factor Analysis (EFA) carried out in the first study confirmed a three-factor structure that explained 57 percent of the variance on the individual level. All items with loadings of less than 0.40 were removed, resulting in the 14 item PEM (Cole, et al., 2012). Confirmatory Factor Analysis (CFA) carried out in the first and second study indicated a good fit of the data to the three-factor model. 
Cross-national and cross-language equivalence was investigated using multi-group CFA. All measures were found to be equivalent across the four language groups and the five countries (Cole, et al., 2012). The use of interviews in test development ensured that the final version of the PEM had high content validity. In addition, both discriminate and predictive validity were established for the PEM. However, reliability and validity in the South African context have yet to be established for the PEM.

\subsection{Transfer of Psychometric Instruments across Different Cultures}

Multiple studies have provided the empirical evidence to substantiate the notion that cultural differences may have an impact on participants' responses to particular psychometric instruments (Van Eeden \& Mantsha, 2007; Meiring, Van de Vijver, \& Rothmann, 2006). This results in the instrument being less valid for specific cultural groups. Although research has confirmed that some psychometric instruments developed in other countries are valid when applied in the South African context (Storm \& Rothmann, 2003), there have also been multiple instances where instruments which were not adapted for use in the South African context resulted in difficulties with reliability and validity (Gray \& Durrheim, 2006; Meiring et al, 2006). This can be attributed to the fact that an individual's subjective culture provides the basis through which they perceive their social environment, which in turn discourages certain behaviors and cultivates others (Anastasi, cited in Schaap, Buys, \& Olckers, 2003). This affects how that individual interprets and responds to the questions posed by a measurement instrument (Prinsloo \& Ebersöhn, 2002).

When determining the cross-cultural validity of a measure, both bias and equivalence should be contemplated. Bias is a broad term which refers to all aspects of measurement which can have a negative impact on the validity of comparisons across cultural groups (Van de Vijver \& Leung, 1997). Equivalence focuses on the level at which comparable observations across cultural groups can be made (Van de Vijver, 2001). There are three types of equivalence, namely construct, measurement and scale equivalence. Construct indicates the extent to which the same construct is measured by a measurement instrument for differing cultural groups. According to Van de Vijver and Poortinga (1997), meaningful comparison of responses from multiple cultural or language backgrounds is dependent on the equivalence of the constructs being measured.

For purposes of this study, emphasis has been placed on determining the construct equivalence of the Productive Energy Measure. Determining construct equivalence is therefore merely the first step in establishing the cross-cultural validity of a measurement instrument. Against this background, the following integrative hypothesis and sub-hypotheses are set for this research:

- Hypothesis 1. Productive Organizational Energy, as measured by PEM, is a three-dimensional construct consisting of an Affective Dimension, a Behavioral Dimension and a Cognitive Dimension. Acceptable internal consistencies exists for all scales and construct equivalence exists for both White and African employees.

- Hypothesis 1.1: Productive Organizational Energy, as measured by the PEM, is a three-dimensional construct consisting of an Affective Dimension, a Behavioral Dimension and a Cognitive Dimension.

- Hypothesis 1.2: Construct equivalence exists for both White and African employees.

- Hypothesis 1.3: Acceptable internal consistencies exist for the PEM.

\section{Research Design}

This research was done using a quantitative approach, as it was considered the best method to address the empirical research objective posed. More specifically, a survey design was used, as this allows for the gathering of quantifiable information that can then be used to determine the impact of trends, attitudes, and opinions within a specific population, as is evident through a sub-set thereof, i.e. the sample of the population (Creswell, 2009).

\subsection{Sampling}

A convenience sample $(\mathrm{N}=304)$ was taken from a diverse group of employees of various organisations in South Africa. According to Hinkin (1995), a minimum of 150 respondents is needed for a developmental study administering productive organisational energy items and validating the items. Another key consideration is the number of subject-to-variable (STV) ratio for factor analyses. Field (2009) maintain that the STV ratio should not be less than 5 for factor analyses. The questionnaire consist of 14 ietms, which meant that the STV ratio was 22. This was close to the minimum STV of 10 respondents per item recommended by Garson (2011). 
The respondents of this sample were primarily females (75.4\%), Married (46.2\%) with their home language as primarily African languages (59.7\%) and representative of the African ethnic group (62\%). Most of the respondents hold and Advanced Diploma as their highest level of qualification (40\%), staff (51.1\%), employed for 0-10 years in their company (58.4\%) and current job (62.2\%). Additional information showed that the respondents were mostly representative of the health care sector (49.2\%), from the Gauteng province (75.1\%) and permanently employed $(91.8 \%)$.

\subsection{Data Collection}

The Productive Organizational Energy Measure (Cole et al., 2005) was used to measure Organizational Energy in this research. The ESP consists of 14 items and measure three dimensions: Cognitive Energy, Affective Energy and Behavioral Dimension. Responses were measured on a five-point Likert-type scale. Acceptable internal consistencies were found for the PEM in previous studies ranging from 0.73 to 0.89 (Cole et al., 2012). The questionnaires were administered electronically to the respondents. Confidentiality of responses was maintained at all times. The research meets all ethical requirements.

\subsection{Statistical Analyses}

Statistical analysis was carried out using the SPSS Program (SPSS Inc., 2013). The reliability and validity of the PEM were determined by means of Cronbach alpha coefficients, as well as exploratory factor analysis. Descriptive statistics (i.e., means, standard deviations, skewness and kurtosis) were used to analyse the data. Construct equivalence of the PEM was also performed. The basic idea behind the application of these techniques is to obtain a structure in each language group which can then be compared across all language groups involved. Factor analysis is the most frequently employed technique for studying construct equivalence. In the current study both exploratory and confirmatory models could have been used. Given that there is information about the composition of the instrument (based on previous studies), the choice of confirmatory factor analysis may seem obvious. However, the current authors used exploratory factor analysis for a pragmatic reason. Although a considerable amount of information exists on the factor structure of the PEM, no studies have been done in the South African context using the PEM.

\section{Results}

\subsection{Sample Adequacy and Sphericity}

The Sampling Adequacy and Sphericity of the inter-item correlation matrix was determined by applying the Kaiser-MeyerOlkin (KMO) measure of sampling adequacy and Bartlett's Test of Sphericity to the inter-item correlation matrix of the PEM. The results of the KMO for the PEM for the African and White groups are presented in Table 1 below.

Table 1: KMO and Bartlett's Test of the Inter Item Correlation of the PEM

\begin{tabular}{|c|c|c|c|}
\hline \multicolumn{2}{|c|}{} & African & White \\
\hline \multicolumn{2}{|c|}{ Kaiser-Meyer-Olkin Measure of Sampling Adequacy } & .915 & .905 \\
\hline \multirow{3}{*}{ Bartlett's Test of Sphericity } & Approx. Chi-Square & 943.355 & 943.355 \\
\cline { 2 - 4 } & Df & 91 & 91 \\
\cline { 2 - 4 } & Sig. & .000 & .000 \\
\hline
\end{tabular}

As evidenced in Table 1 above, the KMO measure for the African group verified the sampling adequacy for factor analysis, since the value of $\mathrm{KMO}$ is 0.915 which is above the 0.6 cut off point set by Hair et al. (2010) and Pallant (2005). Bartlett's Test of Sphericity for the African group was significant $(p<0.05)$ indicating correlations between items were sufficiently large for a factor analysis. Similarly, the KMO measure for the White group verified the sampling adequacy for factor analysis since the value of KMO is 0.905 , and Bartlett's Test for Sphericity is significant $(p<0.05)$. Thus the sample is suitable for further analysis by means of factor analysis. Next we will report on the item-descriptive statistics of the measurement for African and White Ethnic groups. 


\subsection{Item Descriptive Statistics}

Descriptive statistics were used to explore the data. Table 2 below provides the item descriptive statistics of the PEM before the Exploratory Factor Analysis was conducted.

Table 2: Item Descriptive Statistics of the PEM

\begin{tabular}{|c|c|c|c|c|c|c|c|c|}
\hline \multirow{2}{*}{ Item } & \multicolumn{5}{|c|}{ African $(\boldsymbol{N}=\mathbf{1 8 9})$} & \multicolumn{4}{c|}{ White $(\boldsymbol{N}=103)$} \\
\cline { 2 - 9 } & Mean & SD & Skewness & Kurtosis & Mean & SD & Skewness & Kurtosis \\
\hline PEM1 & 3.07 & .896 & -.012 & -.055 & 3.19 & .875 & -.123 & -.350 \\
\hline PEM2 & 3.07 & .812 & .053 & -.175 & 3.25 & .904 & -.201 & -.469 \\
\hline PEM3 & 3.02 & .809 & .215 & .668 & 3.14 & .919 & .111 & -.438 \\
\hline PEM4 & 2.99 & .878 & .010 & .063 & 3.14 & .864 & .011 & .219 \\
\hline PEM5 & 2.95 & .861 & .052 & .134 & 2.68 & 1.012 & .220 & -.166 \\
\hline PEM6 & 3.51 & .903 & -.193 & .044 & 3.74 & .700 & -.989 & 2.136 \\
\hline PEM7 & 3.72 & .838 & -.362 & -.080 & 3.89 & .815 & -1.127 & 2.324 \\
\hline PEM8 & 3.49 & .891 & -.181 & -.312 & 3.84 & .849 & -.676 & .585 \\
\hline PEM9 & 3.37 & .939 & -.090 & -.484 & 3.55 & 1.026 & -.396 & -.591 \\
\hline PEM10 & 3.56 & .975 & -.297 & -.483 & 3.55 & .947 & -.263 & -.211 \\
\hline PEM11 & 3.39 & .997 & -.168 & -.495 & 3.54 & .972 & -.278 & -.350 \\
\hline PEM12 & 3.00 & 1.238 & .102 & -.914 & 3.25 & 1.161 & -.088 & -1.046 \\
\hline PEM13 & 3.26 & 1.018 & -.215 & -.276 & 3.61 & .819 & -.258 & -.375 \\
\hline PEM14 & 3.10 & 1.027 & .046 & -.355 & 3.46 & 1.017 & -.278 & -.488 \\
\hline
\end{tabular}

Table 2 provides an overview of the number of valid cases per group for each of the 14 variables of the PEM, measures of central tendency and dispersion. The data is divided into two groups, namely African and White. The African Group consists of a total 189 respondents, while the white group consists of 103 respondents in total. A five-point response scale was used ranging from "Never" to "Frequently, if not Always" on the Affective Dimension, and "strongly disagree" to "strongly agree" on the Cognitive and Behavioral Dimensions. The mean values for the African group range between 2.96 and 3.72 and for the White group range between 2.68 and 3.89. This indicates that the both the African and the White Groups tended to average or middle of the range answers.

Standard Deviation values for the African Group range between 0.809 and 1.238, and between 0.700 and 1.161 for the White Group, indicating a small degree of dispersion. The skewness values for the White group range between 1.127 and 0.220 , indicating a negatively skewed distribution. Similarly, the African Group also presented a distribution which was negative, however the skewness values were lower than the white group, and ranged between -0.362 and 0.215 . The kurtosis values for the African group range between -0.914 and 0.668 , and for the White group range between -1.046 and 2.324. Next we report on the results of the exploratory factor analysis.

\subsection{Results of the Exploratory Factor Analysis}

Firstly, a principal component analysis was conducted on the 14 items of the PEM to determine the number of factors of the PEM in the total sample. The 14 items of the PEM were inter-correlated and the eigenvalues of the unreduced intercorrelation matrix were calculated. The results showed that three factors had eigenvalues larger than 1 and were extracted for further analysis. In the African group, the three factors contributed to 68.566 percent of the initial Eigen variance and 60.258 percent of the Extraction Sums of Squared Loadings. This means that for the African group, three factors account for 60.258 percent of the total variance explained. In the White group, the three factors contributed to 70.776 percent of the initial Eigen variance and 63.213 percent of the Extraction Sums of Squared Loadings. This means that for the White group, three factors account for 63.213 percent of the total variance explained. The pattern matrices for the African and White respondents are reported in Table 3 below. 
Table 3: Pattern Matrices for the African and White Groups

\begin{tabular}{|c|c|c|c|c|c|c|c|}
\hline & & \multicolumn{3}{|c|}{ Factor: African } & \multicolumn{3}{|c|}{ Factor: White } \\
\hline & & 1 & 2 & 3 & 1 & 2 & 3 \\
\hline PEM1 & People in my work group feel excited in their job & .044 & -.861 & .102 & .029 & -.884 & .077 \\
\hline PEM2 & People in my work group feel enthusiastic in their job. & .187 & -.751 & .055 & .230 & -.717 & -.028 \\
\hline PEM3 & People in my work group feel energetic in their job. & -.009 & -.738 & -.175 & .069 & -.891 & .005 \\
\hline PEM4 & People in my work group feel inspired in their job. & -.065 & -.850 & -.059 & .069 & -.829 & -.018 \\
\hline PEM5 & People in my work group feel ecstatic in their job. & .018 & -.747 & -.069 & -.184 & -.861 & -.103 \\
\hline PEM6 & My work group is ready to act at any given time. & .621 & -.158 & -.018 & .548 & -.118 & -.047 \\
\hline PEM7 & People in my work group are mentally alert. & .802 & -.044 & .114 & .908 & .105 & .057 \\
\hline PEM8 & In my work group there is a collective desire to make something happen. & .712 & -.093 & -.058 & .600 & -.062 & -.219 \\
\hline PEM9 & People in my work group really care about the fate of this company. & .511 & -.063 & -207 & .077 & -.056 & -.728 \\
\hline PEM10 & People in my work group are always on the lookout for new opportunities. & .411 & .034 & -.266 & -.041 & .009 & -.670 \\
\hline PEM11 & People in my work group will go out of their way to ensure the company succeeds & .321 & .089 & -.534 & .010 & .050 & -.902 \\
\hline PEM12 & People in my work group often work extremely long hours without complaining. & -.090 & -.091 & -.745 & .202 & -.150 & -.458 \\
\hline PEM13 & There has been a great deal of activity in my work group. & .017 & -.115 & -.738 & .422 & -.155 & -.238 \\
\hline PEM14 & People in my work group are working at a very fast pace. & .205 & -.120 & -.601 & .544 & -.123 & -.056 \\
\hline
\end{tabular}

The pattern matrix for the African Group illustrates the factor loadings of each item onto each of the three factors (Field, 2009). Items PEM6 to PEM10 loaded on the Factor 1 for the African Group with strong factor loadings ranging from 0.411 to 0.802 . Items PEM1 to PEM 5 loaded on the Factor 2, with strong factor loadings ranging from 0.738 to 0.861 . Items PEM11 to PEM14 loaded on the Factor 3 Dimension, with factor loadings ranging from 0.534 to 0.745 . Although PEM11 also had a factor loading of 0.321 on the Factor 1 , it is below the 0.35 value required by Hair et al. (2010) to distinguish cross loadings. Thus PEM11 for the African Group can be retained without adjustments.

The pattern matrix for the White Group illustrates the factor loadings of each item onto each of the three factors (Field, 2009). Items PEM6 to PEM8 loaded on the Factor 1 for the African Group with strong factor loadings ranging from 0.548 to 0.908 . However, PEM9 and PEM10 loaded on Factor 3 with strong factor loadings of 0.728 and 0.670 respectively. Items PEM1 to PEM 5 loaded on the Factor 2, with strong factor loadings ranging from 0.717 to 0.891 . PEM11 and PEM12 loaded on the Factor 3 Dimension, with factor loadings of 0.902 and 0.458 respectively. However, PEM13 and PEM14 loaded on Factor 1 with factor loadings of 0.422 and 5.44 .

The factor labels proposed by Cole et al. $(2011 ; 2005)$ were confirmed by the extracted factors for the African Group. The three factors were labeled as follows: Cognitive Dimension (factor 1); Affective Dimension (factor 2) and Behavioral Dimension (factor 3). However, the items for the Cognitive and Behavioral Dimension for the African and White Group loaded differently. The pattern matrices for the three-factor solution for the African and White participants were therefore used as inputs for an EFA with target rotations.

Factors obtained in each group were compared by using a factor congruence coefficient, Tucker's phi (Van de Vijver \& Leung, 1997). Values above 0.90 are taken to point essential agreement between cultural groups, while values above 0.95 point to very good agreement. A high agreement implies that the factor loadings of the lower and higher levels are equal up to a multiplying constant. The following Tucker's phi coefficients were obtained: Affective $=0.92$; Cognitive $=0.98$ and Behavioral $=0.96$. All three coefficients were above the minimum value required to interpret essential agreement. Furthermore, coefficients for the Affective and Cognitive dimensions were both above 0.95, indicating very good agreement. Since these coefficients compared favorably with the guideline of 0.90 and can therefore be regarded as acceptable. These results indicate construct equivalence two ethnic groups.

The factor correlation matrix indicates the strength of the association between the factors, or the extent to which the factors are distinct and unrelated, also known as discriminant validity. A correlation of 0.3 and above is considered significant. However, the correlations between factors should not exceed 0.7 , as this indicates a majority of shared variance between the factors (Hair et al., 2010). The factor correlation matrix for both the African and the White groups is presented in Table 4 below. 
Table 4: Factor Correlation Matrix for African and White Groups

\begin{tabular}{|c|c|c|c|c|c|c|}
\hline \multirow{2}{*}{ Factor } & \multicolumn{3}{|c|}{ African } & \multicolumn{3}{c|}{ White } \\
\cline { 2 - 7 } & Affective & Cognitive & Behavioral & Affective & Cognitive & Behavioral \\
\hline Affective & 1.000 & -.595 & -.561 & 1.000 & -.538 & -.598 \\
\hline Cognitive & -.595 & 1.000 & .495 & -.538 & 1.000 & .630 \\
\hline Behavioral & -.561 & .495 & 1.000 & -.598 & .630 & 1.000 \\
\hline
\end{tabular}

From the results in Table 4 it is clear that all the factor correlations are above the 0.3 value which Hair et al. (2010) recommend for interpreting correlations. It is also worth noting that no factors are equal to or greater than 0.7 . It is therefore evident that the three factors can be clearly distinguished from each other. The test for normality of the measure is reported next.

Kolmogorov-Smirnov Test for normality was carried out on the PEM on both African and the White groups to determine the normality of the scale obtained in the factor analysis. The results of the normality tests are summarized in Table 5 below.

Table 5: Normality Tests for the PEM for African and White Groups

\begin{tabular}{|c|c|c|c|}
\hline \multicolumn{2}{|c|}{} & $\begin{array}{c}\text { PEM Ave } \\
\text { African }\end{array}$ & $\begin{array}{c}\text { PEM Ave } \\
\text { White }\end{array}$ \\
\hline \multicolumn{2}{|c|}{$\mathrm{N}$} & 189 & 102 \\
\hline \multirow{2}{*}{ Normal Parameters } & Mean & 3.2435 & 3.4284 \\
\cline { 2 - 4 } & Std. Deviation & .66690 & .67040 \\
\hline \multirow{3}{*}{ Most Extreme Differences } & Absolute & .050 & .092 \\
\cline { 2 - 4 } & Positive & .044 & .049 \\
\cline { 2 - 4 } & Negative & -.050 & -.092 \\
\hline \multicolumn{2}{|c|}{ Kolmogorov-Smirnov Z } & .688 & .926 \\
\hline \multicolumn{2}{|c|}{ Asymp. Sig. (2-tailed) } & .732 & .357 \\
\hline
\end{tabular}

The $z$ statistic for the African and White groups is .688 and .926 respectively. Both these values are non-significant $(p \geq$ 0.05), indicating that the scale for both groups conforms to normality. This indicates that the PEM is suitable for parametric statistical procedures. The descriptive statistics of the three factors are reported in Table 6 below.

Table 6: Total Descriptive Statistics of the Three Factors of the PEM

\begin{tabular}{|l|c|c|c|c|c|}
\hline & Mean & Std. Deviation & Skewness & Kurtosis & $\alpha$ \\
\hline Affective Dimension & 3.0368 & .76591 & .041 & .199 & .918 \\
\hline Cognitive Dimension & 3.6020 & .71196 & -.404 & .167 & .822 \\
\hline Behavioural Dimension & 3.2805 & .85575 & -.180 & -.334 & .829 \\
\hline
\end{tabular}

It is apparent that the scales of the PEM have relatively normal distributions, with low values of skewness and kurtosis. Standard Deviation values for all three scales indicate a small degree of dispersion. Cronbach's Alpha values for the affective ( $\alpha=0.918$ ) dimension indicated a high level of consistency, and could be described as excellent" (Field, 2009). Similarly, the Cronbach's Alpha values for the cognitive $(\alpha=0.822)$ and behavioural $(\alpha=0.829)$ dimensions indicated high levels of internal consistency and could be described as good (Field, 2009). Considering that a five-point scale was utilized for responses, it is evident that the respondents tended to have average scores on all three dimensions, with the cognitive dimension scores being marginally higher those of the behavioural dimension, and the affective dimension respectively. The above results confirm the integrative hypothesis as well as the sub-hypotheses.

\section{Discussion and Conclusion}

Despite a proliferation of literature on the concept of organizational energy, there is still a considerable lack of valid research instruments to measure it in the workplace. This research aimed to validate the Productive Organizational Energy Measure in the South African context. The results showed a three-factor solution for the 14 items if the PEM 
based on the EFA target rotations. Although the factor loadings of the items on the three factors revealed by the EFA did differ slightly for the Indigenous and White groups, the greater part of the EFA data substantiates the three factors identified by Cole et al. $(2005 ; 2012)$, namely the affective, behavioral and cognitive dimensions.

The results of the EFA indicated that the 14 items of the PEM loaded as expected on the three underlying factors for the Black ethnic group. The factor labels proposed by Cole et al. $(2012 ; 2005)$ were confirmed by the extracted factors for the Indigenous Group. These three factors are labeled as follows Cognitive Dimension (Factor 1); Affective Dimension (Factor 2) and Behavioral Dimension (Factor 3). While the items of the PEM loaded similarly on the Affective dimension for the White group, the items for the Cognitive and Behavioral dimensions of the Indigenous and White Group loaded differently. In particular, two items from each factor proved problematic in the data from the White group, and were examined from an item structure point of view. Item PEM9 "People in my work group really care about the fate of this company" and item PEM10 "People in my work group are always on the lookout for new opportunities" did not load as anticipated on the cognitive dimension, but rather loaded on the behavioral dimension.

The wording in item PEM9 suggests that the link between caring about the fate of the company, and Cognitive energy, may not be clear to respondents. Item PEM10 seems to be ambiguous, as it does not indicate what type of opportunities people could be on the lookout for. Such opportunities could be understood as being related to the prospects for the organization or work group. Alternatively, such opportunities could also be understood by respondents as implying personal opportunities for the individual not related to the organization or work group. Similarly, Item PEM13 "There has been a great deal of activity in my work group", and Item PEM14 "People in my work group are working at a very fast pace", did not load as anticipated on the behavioral dimension, but loaded on the cognitive dimension.

Consequently, it is suggested that these four items be reworded so that their meaning is more clearly articulated to respondents. It is anticipated that this could result in the items loading on the correct factor. However, the possibility of adding additional new items for the two problematic factors (the Cognitive and the Behavioral dimensions) should be investigated further, as this may result in items which explain the factors more appropriately. Moreover, the White group consisted of individuals who spoke two different home languages. The split was approximately half between English and Afrikaans. This could indicate that there are differences between how a native English speaking individual understood and interpreted the questions as opposed to a native Afrikaans speaker. As mentioned by Van de Vijver and Poortinga (1997) the cultural backgrounds of individuals can have a significant impact on how tests are interpreted. It is therefore possible that the cultural background of the different Indigenous groups, the English-speaking White group, and the Afrikaans-speaking White group had an impact on their interpretation of productive energy in the workplace. Interestingly, though the Indigenous group had varied Indigenous languages as their first language, they seemed to interpret the questions as intended by the PEM Test Developers.

The pattern matrices for the three-factor solution for Indigenous and White participants were used as inputs for an EFA with target rotations, which resulted in all three dimensions demonstrating high Tucker's phi values. All three coefficients were above the minimum value required to interpret essential agreement. Furthermore, coefficients for the Affective and Cognitive dimensions indicated very good agreement. These results imply essential agreement between the Indigenous and White cultural groups, and thus construct equivalence (Van de Vijver \& Leung, 1997). Therefore, construct equivalence for the PEM for the two groups on the cognitive and behavioral dimensions is present and subhypothesis $1 \mathrm{~b}$ is accepted. Finally the results showed good to excellent internal consistencies for the three dimensions of productive oragnisational energy ranging from 0.829 to 0.918 . These results thus confirm the reliability of the Productive Organisational Energy measure in the South African context (see Cole et al., 2005; 2012).

\subsection{Implications of the study}

This research made and important contribution towards new knowledge regarding the psychometric properties of the PEM. Methodologically this research confirms the utility of the PEM as a valid and reliable measure of productive organizational energy in a diverse context such as South Africa. From a practical point of view this research shows that the PEM can be used as a diagnostic tool to assess individual perceptions of energy within their teams. This is an important contribution as individuals collaboratively play an important role in achieving the key strategic objectives of the organization and at the same time ensures that the organization remains sustainable.

\subsection{Limitations and Recommendations}

This research had some limitations. First a lack of literature and empirical research currently exists on organizational 
energy, which makes it difficult to interpret the findings. Second this research relied on self-report measures which may increase the likelihood that at least part of the shared variance between measures can be attributed to method variance. The results of this study have provided valuable insights into both the nature of productive organizational energy, and the phenomenon in the South African workplace. However, it is clear that more research is needed to clarify the concept of productive organizational energy in the South African context. The focus of the empirical portion of this study was primarily examining measurement of the individual level of the experience of organizational energy using the PEM. While the individual level of organizational and productive energy is an important area of research, it is important that further studies in the both the international and the South African contexts examine the collective level of energy, as well as the manifestation of the proposed multi-level emergent phenomenon. Cole et al. (2012) therefore recommended that forthcoming studies examine "cross-level effects from unit-level productive energy to individual's psychological capacities". Cole et al. (2012) for example undertook studies to determine the relationship between productive organizational energy and its contribution to unit or organizational effectiveness and collective outcomes such as collective motivation, collective efficacy, group cohesion, collective autonomy, and collective exhaustion. It is recommended that these areas be further investigated in the South African context.

\subsection{Conclusion}

In conclusion, this study has demonstrated the significance of energy in organizations, and how important it is to actively manage the interactive and dynamic relationship between the organization and its members to the mutual benefit of both parties. This can be achieved by monitoring energy levels in the organization on a continuous basis to ensure that elements which contribute to productive organizational energy are cultivated and nurtured. Similarly, elements which are depleting the energy in the organization can be identified and managed. The outcomes of the present study will enlighten those interested in measuring organizational energy in the workplace. The results of this measurement of organizational energy can be used to assist organizations in identifying practices, processes and initiatives which can have a positive impact on organizational energy and in turn, on productivity and the satisfaction levels of their employees. Using this information, interventions which facilitate productive organizational energy or address energy challenges can then be developed.

\section{Acknowledgement}

We would like to thank M.S. Cole for granting permission to use the Productive Energy Measure.

\section{References}

Barkhuizen, E.N. \& Stanz, K.J. (2010). Linking organisational energy and individual well-being: The Influence of Leader's Talent Mindset, Peer reviewed conference proceedings of the $12^{\text {th }}$ Annual Conference of Global Business and Technology Association, Kruger National Park, South Africa, 5-9 July, . 50- 57, Gbata, USA, ISBN: 1-932917-06-3

Bell, E. \& Barkhuizen, E.N. (2011). The relationship between barriers to change and work engagement of employees in a South African property management company. South African Journal of Industrial Psychology 37, 1-11.

Brown, D.B. (2011). An Experiential Approach to Organisation Development (8th Ed.), Pearson Education Inc., Uer Saddle River, New Jersey.

Bruch, H., \& Ghoshal, S. (2003). Unleashing organisational energy. MIT Sloan Management Review, Fall, 5-51.

Bruch, H. \& Vogel, B. (2011). Fully Charged: How Great Leaders Boost their Organisation's Energy and Ignite High Performance. Boston, Massachusetts: Harvard Business Review Press.

Cameron, K. S. \& Spreitzer, G. M. (2011). The Oxford Handbook of Positive Organisational Scholarship. New York: Oxford University Press.

Cannon-Bowers, J. A. \& Salas, E. (2001). Reflections on shared cognition, Journal of Organisational Behaviour, 22, 195-202.

Cole, M. S., Bruch, H. \& Vogel, B. (2008). Productive energy in the workplace: a measurement validation and linkage to collective outcomes. Fort Worth, TX.

Cole, M. S., Bruch, H. \& Vogel, B. (2012). Energy at work: A measurement validation and linkage to unit effectiveness. Journal of Organizational Behavior, 33, 445-467.

Cresswell, J. W. (2009). Research Design: Qualitative, Quantitative and Mixed Methods Approaches (3rd Ed.), Thousand Oaks: Sage Publications.

Cross, R., Baker, W. \& Parker, A. (2003). What creates energy in organizations? MIT Sloan Management Review, 44(4), 51-56.

Cummings, T.G. \& Worley, G.W. (2008). Organisation Development and Change (9th Ed.). Mason, OH: South-Western Cengage Learning. 
Derman, L. (2009). Organisational energy and individual wellbeing. Unpublished Doctoral Thesis, University of Johannesburg.

Dutton, J. E. (2003). Energize your workplace: how to create and sustain high-quality connections at work. San Francisco: Jossey Bass.

Field, A. (2009). Discovering statistics using SPSS (3 ${ }^{\text {rd }}$ ed.). London: Sage.

Furr, R. M. (2011). Scale construction and psychometrics for social and personality psychology. London, UK: Sage Publishing.

Gray, D. \& Durrheim, K. (2006). The validity and reliability of measures of right-wing authoritarianism in South Africa. South African Journal of Psychology, 36, 500-520.

Hinkin, T. R. (1995). A review of scale development practices in the study of organizations. Journal of Management, 21, 967-988.

Lawler, E. \& Mohrman, S. (2003). HR as a strategic partner: what does it take to make it haen? Human Resources Planning, 26(3), 1529.

Lawler, E. E. (2005). Strategic Human Resource Management. Los Angeles: Centre for Effective Organisations.

Luthans, F. \& Avolio, B. (2009). The point of positive organisational behviour. Journal of Organizational Behavior, 30, 291 - 307.

Meiring, D., Van de Vijver, F. J. \& Rothmann, S. (2006). Bias in an adapted version of the 15FQ+ in South Africa. South African Journal of Psychology, 36, 340-356.

Prinsloo, C. H. \& Ebersöhn, I. (2002). Fair usage of the 16PF in personality assessment in South Africa: A response to Abrahams and Mauer with special reference to issues of research methodology. South African Journal of Psychology, 32, 48-57.

Salas, E. \& Fiore, S. M. (2004). Team cognition: Understanding the factors that drive process and performance. Washington: APA Press.

Schaap, P., Buys, M. A. \& Olckers, C. (2003). The construct validity of Scheeper's locus of control inventory for black and white tertiary students. South African Journal of Industrial Psychology, 29, 32-43.

Schiuma, G., Mason, S. \& Kennerly, M. (2007). Assessing energies within organisations. Measuring Business Excellence, 11, 69-78.

Spreitzer, G. M., Sutcliffe, K., Dutton, J. E., Sonenshein, S. \& Grant, A. M. (2005). A socially imbedded model of thriving at work, Organisation Science, 16, 537-549.

SPSS Inc. 2013. SPSS 21 for Windows, Chicago, IL: Author.

Storm, K. \& Rothmann, S. (2003). A psychometric analysis of the Maslach Burnout Inventory-General Survey in the South African police service. South African Journal of Psychology, 33, 219-226.

Van de Vijver, F. J. (2001). The evolution of cross-cultural research methods, In D. R. Matsumoto (Ed.), Handbook of culture and psychology (pp. 77-97). New York: Oxford University Press.

Van de Vijver, F. J. \& Leung, K. (1997). Methods and data analysis for cross-cultural research. Thousand Oaks, California: Sage Publishers.

Van de Vijver, F. J. \& Poortinga, Y. H. (1997). Towards an integrated analysis of bias in cross-cultural assessment. European Journal of Psychological Assessment, 13, 29-37.

Van Eeden, R. \& Mantsha, T. R. (2007). Theoretical and methodological considerations in the translation of the 16PF5 into an African language. South African Journal of Psychology, 37, 62-81.

Vogel, B., \& Bruch, H. (2011). Organisational energy. In K. S. Cameron, \& G. M. Spreitzer (Eds.), The Oxford Handbook of Positive Organisational Scholarship (pp. 691-702), New York: Oxford University Press. 